\title{
TEN STRATEGIC POINTS: A FRAMEWORK FOR DOCTORAL DISSERTATIONS STUDENTS TO CONCEPTUALIZE THEIR RESEARCH DESIGN IN A DOCTORAL RESIDENCY PROGRAM
}

\author{
Cynthia Bainbridge, Grand Canyon University \\ June Maul, Grand Canyon University \\ Cristie McClendon, Grand Canyon University
}

\section{ABSTRACT}

This study examines doctoral student perceptions regarding learning acquired during a weeklong residency program wherein they were exposed to a strategic framework designed to help conceptualize the design for their dissertation study. Using a simple quantitative, pre-experimental, one group prepost-test, design, a questionnaire was developed to measure student perceptions. During the residency, students are taught this framework which is founded on theories and models from the fields of education and psychology. The 10-point model provides a multifaceted approach to enabling doctoral students to conceptualize the design for their own doctoral dissertation working within an environment that supports cognitive and social development. This approach provides students with a model and faculty feedback to create an aligned research study early in their program of study. Students responded to 15 questions regarding their understanding of the 10 required components of the study on Day 2 and again on Day 4 of the residency. Data were analyzed using Wilcoxen Signed Rank Test. The results indicated there was significant improvement in student self-reported learning and understanding of the various elements of the 10 strategic points model between the pre-posttest results.

Keywords: dissertation, research design, doctoral students, research, cognitive development, constructivism, mental models, experiential learning

\section{INTRODUCTION}

As the number of doctoral programs continues to grow among universities across the United States, there is a need to address a number of the challenges these institutions and their students face. Attrition rates are high in doctoral programs for education, ranging from $50 \%$ (Ivankova \& Stick, 2007) to as high as $70 \%$ (Nettles \& Millet, 2006). Additional problems for these programs can include unexpected and lengthy amounts of time to degree completion and lack of preparation on the part of the doctoral students (Anderson, Cutright, \& Anderson, 2013). In 2008, the time it took to complete a doctoral degree was estimated as between 7 and 12 years (Wao \& Onwuegbuzie, 2011). Furthermore, over the past two decades, doctoral education has been the focus of heightened attention, due to increased accountability and interest in the effectiveness of these programs (Anderson et al., 2013).

While there are some challenges associated with the structure of and completion rates in doctoral programs, the attainment of a doctoral degree has significant benefits for doctoral students, as well as for the institutions and organizations they will work in the future. Doctoral students contribute to the creation of new ideas and approaches to learning across academic institutions (Davis, Evans, \& Hickey, 2006). Thus, obtaining a doctorate provides career opportunities for students as they begin to apply their scholarly leadership in the job market. Additionally, through applying their research skills and experience, graduates can forge relationships 
between academia and outside organizations (Thune, 2009). The development of these new academic leaders is incumbent upon universities providing effective and timely programs.

To address challenges and to further realize these opportunities, it is important to improve the effectiveness and efficiency of doctoral programs. Recent research identified various factors that are important when considering the design of doctoral programs (Jones, 2013). Pertaining to academics, there have been recommendations that promote a structured, systematic curriculum and milestones in these programs (Anderson et al., 2013). Socialization, which involves adapting the values, knowledge and capabilities in a given society, is also important for the success of the doctoral learner. Innate psychological needs, such as autonomy and a sense of relatedness, may provide the motivation needed to be successful in doctoral programs (Mason, 2012). Gardner (2010) found that "faculty members' contributions to the socialization of students go beyond the explicit expectations as determined in the faculty role, including teaching, advising, and career preparation, to the more implicit expectations of their behaviors, mannerisms, and attitudes" ( $p$. 49-50). Universities are providing additional focus on developing the research skills and the pedagogy to address this need (Wagner, Garner, \& Kawulich, 2011).

Doctoral students often experience a lack of knowledge and preparedness as they begin the dissertation phase of the program, perhaps the most challenging part of the degree. This phase requires extraordinary effort and persistence on the part of the learner (Lindsay, 2015). A systematic and carefully designed approach and support systems can facilitate their journey, success, and persistence through this process. There is greater need, though, to create an understanding of the structure of these supports and how they improve student understanding of the foundational design elements of their dissertation study. This article presents a 10-point strategic framework students can use to create a design for their own doctoral research study within a doctoral residency that focuses on enabling their cognitive, social, and emotional development.

\section{PURPOSE OF THE STUDY}

The purpose of this study was to determine doctoral students' perceptions of the learning they gained from the use ofa 10-point strategic framework within the context of this weeklong residency program in an online Ed.D. doctoral program at a university located within the southwestern United States. Doctoral students completed a selfassessment of their level of understanding of how to conceptualize and develop each of the components of the 10-point strategic framework for their own dissertation research at the beginning and end of the residency program. The following research question guided this study:

1. How did participation in a weeklong residency program focused on experiential and social learning change doctoral students' perceived level of knowledge regarding their ability to conceptualize a 10 -point strategic framework for their dissertation study?

\section{THEORETICAL FOUNDATIONS AND GUIDING FRAMEWORKS}

\section{Experiential Learning and Constructivism}

The theoretical foundations of experientialbased learning and constructivism provide the basis for the design of the learning environment, within which, the student uses this strategic framework to conceptualize the design for their research study. This approach to learning enables doctoral students to design and conduct research successfully to complete their dissertations within an online doctoral program in a timely fashion. The use of experiences, which engage students socially and emotionally, and at the same time, facilitate their cognitive development through a constructivist approach to learning, are hoped to contribute to the successful complete of doctoral dissertations as well as reduced cycle times by providing the skills and motivation needed. This study focused on obtaining the students' perceptions of the learning they gained from the use of this strategic framework within the context of this one-week residency program.

The focus of the weeklong doctoral residency program is to provide doctoral students the opportunity to develop a 10-point strategic framework for the design for their own doctoral dissertation. This process involves developing knowledge in research, as well, as developing the cognitive ability to construct the elements of the 
design and approach for the research study. Wagner et al. (2011) argued that there is a need to create a pedagogical culture focused on enabling students to learn the art of research. They presented arguments to support Brew's (2003) perspective that research approaches should be developed, or constructed by the student, rather than transmitted by the faculty member. This method of teaching research in doctoral programs reflects the constructivists' approach to learning, which involves the student exploring, discovering, and inventing, thus enabling learning in more robust ways (Alfieri, Brooks, Aldrick, \& Tenenbaum, 2010). The student becomes the center of learning as they manipulate their world of research with the intent to make sense of that work and generate new mental models (Piaget, 1980). Constructivists pose that students learn, not through receiving information from teachers, but rather through active engagement with their environment where they form new knowledge and models (Raskin, 2002).

With regard to the 10-point strategic framework, students use mental or visual models, with carefully orchestrated guidance from faculty to envision, construct, and design their own research study. Visual models and pictures help people to comprehend new knowledge and create their own mental models for future use (Glenberg \& Langston, 1992). The visual and representational information can help a person integrate information derived from propositional and perceptual materials. Glenberg and Langston (1992) provided this example to illustrate this integration:

.... a text could describe features of an object (e.g., its mass and density), a picture could indicate the object's location in space, and the representational element in the mental model could link the information sources so that they are conceived of as pertaining to the same object. (p. 5)

The use of mental models enables a person to "notice" that which enhances their comprehension of the information (Glenberg \& Langston, 1992). Then, as the mental model is developed, the student focuses attention on or notices the new element. Use of pictures or visuals not only help to construct the mental model, but also help to manage the mental models in the working memory (Glenberg \& Langston, 1992). The 10-point strategic framework helps students "visualize" their study, along with the interconnectedness of the key components of their dissertation research plan.

\section{Primary Components of the Residency Program} Enabling Students to Design their Research

There are three primary components of the residency program that enable the students to design the 10-point strategic framework for their own research. First, a visual mental model for research is presented. Secondly, students spend over $50-60 \%$ of the time in class working on designing the 10-point strategic framework for their own proposed doctoral dissertation. Finally, faculty members are experienced highly qualified dissertation chairs that have successfully coached a number of students through the dissertation process. Additionally, these faculty members support and coach other chairs, assuming the role of coaches, rather than teachers. This framework or design was supported by Walker, Golde, Jones, Bueschel, and Hutchins (2008) who suggested that doctoral students benefit from experiential learning, engaging in exchange of ideas and dialogue with experienced researchers and faculty members. Furthermore, the use of deliberately framed guidance, specific and constructive feedback, and engaging social interaction, improves the student's ability to think about their study. The students are able to make a connection between their prior coursework, where they learned the content related to their study and the research skills they are developing to execute their data collection and write the dissertation. Curricula, which facilitate these connections, such as the week-long residency, help students transition from their coursework to the dissertation phase of their program, improving the likelihood of their persistence (Jimenez, 2011). Finally, an opportunity for students to interact with their cohorts and faculty facilitates social connectedness to the university, but also fosters the development of these needed knowledge and skills. A sense of community and social connectedness is very important during the dissertation process in an online university, where students tend to feel isolated and alone (de Valero, 2001). 
Strategic Framework: Ten Strategic Points Define the Research Architecture

The mental model presented as the basis for the students to create the strategic framework for their research is entitled "The 10 Strategic Points for Research." This conceptual framework was developed to present a simple, mental model of the 10-key elements of any research design. This model comprises 10 defined elements, visualization of their interaction, and a set of questions that help the student ensure the 10 research elements are aligned. Figure 1 illustrates each of the 10 components of this mental model. It also illustrates the flow of the components, as well as, some of the interactions between the components. Table 1 describes each of the components and identifies the questions that help to ensure the alignment of the various components. Although the table describes what appears to be a simple set of sequential steps to develop each of the components. In the end, this process is iterative throughout the residency program and in future courses, where students define their final 10-point strategic framework for their dissertation research.

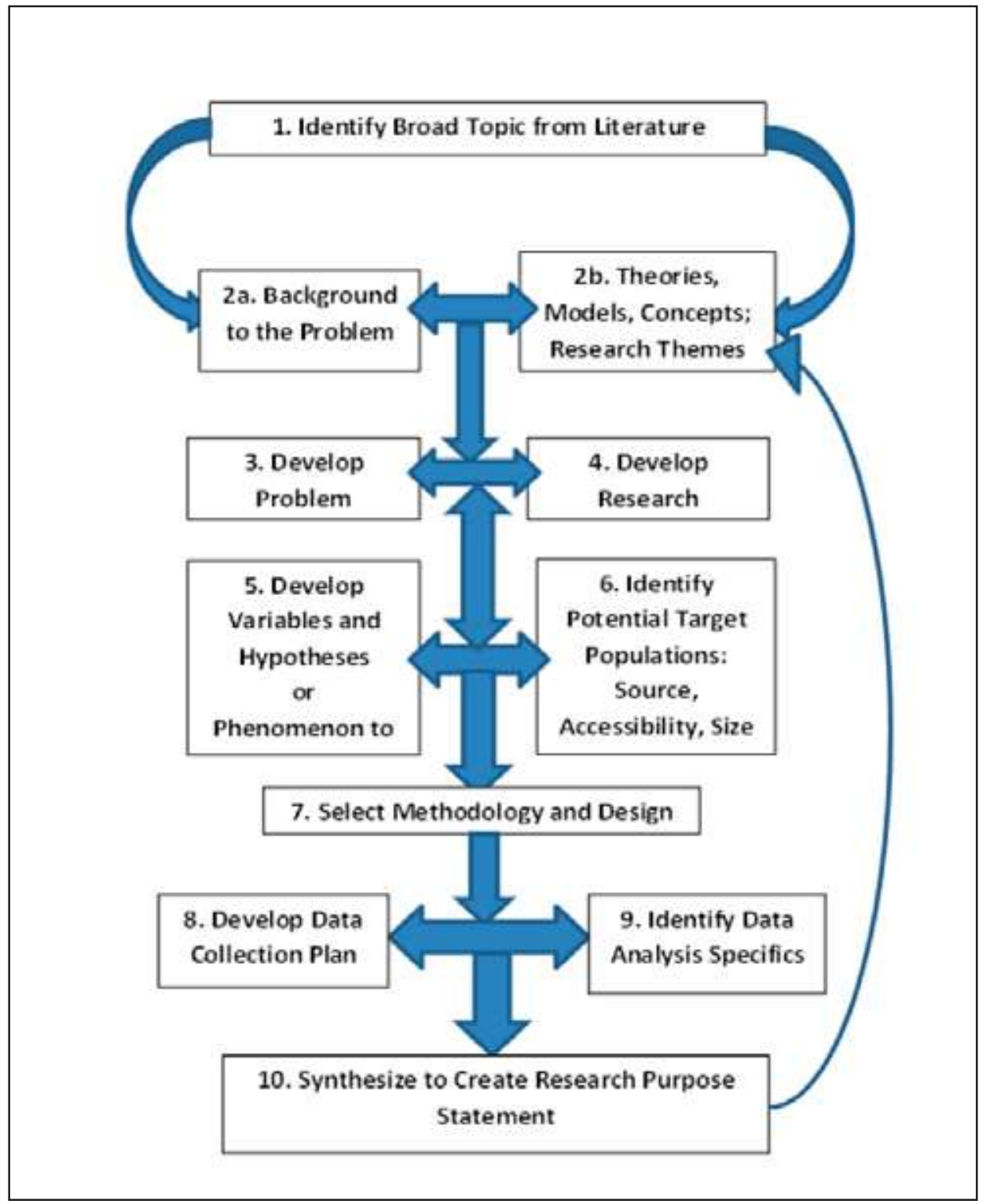

Figure 1. The mental model for the 10-point strategic framework showing sequence of steps and interaction between the components. 
Table 1: Ten-point strategic framework components and alignment questions

\begin{tabular}{|c|c|c|}
\hline 10 POINTS & DESCRIPTION OF EACH COMPONENT & QUESTIONS TO ENSURE ALIGNMENT \\
\hline 1. Identify broad topic from the literature & $\begin{array}{l}\text { Identify a broad topic area to research that } \\
\text { addresses personal passion, future career purpose, } \\
\text { and degree specialization. }\end{array}$ & $\begin{array}{l}\text { - Is the topic aligned with your passion? } \\
\text { - Career purpose? } \\
\text { - Degree being pursued? }\end{array}$ \\
\hline 2a. Describe background to the problem & $\begin{array}{l}\text { Complete a review of the literature to define the } \\
\text { background to the problem including the need or } \\
\text { gap the dissertation research will address. Use this } \\
\text { background to develop the problem statement in } \\
\text { Step } 3 .\end{array}$ & $\begin{array}{l}\text { - Does the literature define a clear need to conduct } \\
\text { the proposed research? } \\
\text { - Does this need address a passion, career purpose, } \\
\text { and degree specialty focus? }\end{array}$ \\
\hline $\begin{array}{l}\text { 2b. Identify theories, models, concepts } \\
\text { and research themes }\end{array}$ & $\begin{array}{l}\text { Identify potential models, theories, and concepts } \\
\text { to provide the theoretic framework for conducting } \\
\text { the research. Identify research topics and themes } \\
\text { related to the research topic that will help frame the } \\
10 \text { points. Use the models, theories, and/or concepts } \\
\text { to develop the research question in Step } 4 \text {. }\end{array}$ & $\begin{array}{l}\text { Do the selected concepts, models, and theories } \\
\text { provide a theoretical basis for researching the } \\
\text { stated need or gap? }\end{array}$ \\
\hline 3. Develop problem statement & $\begin{array}{l}\text { Develop a clear, simple, one-sentence problem } \\
\text { statement that defines the problem, or gap, which the } \\
\text { research will address. }\end{array}$ & $\begin{array}{l}\text { - Does the problem statement clearly and simply } \\
\text { describe a need or gap defined by the literature? }\end{array}$ \\
\hline 4. Develop research questions & $\begin{array}{l}\text { Develop a set of research questions that will define } \\
\text { the data needed to address the problem statement. }\end{array}$ & $\begin{array}{l}\text { Will these research questions collect data needed } \\
\text { to address the problem statement and to answer } \\
\text { the research questions? }\end{array}$ \\
\hline $\begin{array}{l}\text { 5. Develop variables and hypotheses or } \\
\text { phenomenon to study }\end{array}$ & $\begin{array}{l}\text { Describe the phenomenon to be studied (if it is a } \\
\text { qualitative study), or develop hypotheses that define } \\
\text { the variables that will be the focus for the research (if } \\
\text { it is a quantitative study). }\end{array}$ & $\begin{array}{l}\text { Does the phenomenon described (or hypotheses } \\
\text { and variables proposed) clearly relate to the } \\
\text { problem statement, theories/models/concepts, } \\
\text { and research questions? }\end{array}$ \\
\hline $\begin{array}{l}\text { 6. Identify potential target populations, } \\
\text { source, accessibility, and size }\end{array}$ & $\begin{array}{l}\text { Identify potential target population the researcher } \\
\text { could gain access to for collecting the data, } \\
\text { considering that quantitative study sample sizes } \\
\text { should be larger than those for qualitative studies. }\end{array}$ & $\begin{array}{l}\text { Will the target population (individuals or } \\
\text { organizations) be able to provide the data to } \\
\text { answer the research questions (qualitative) or } \\
\text { test the hypotheses (quantitative)? }\end{array}$ \\
\hline 7. Select methodology and design & $\begin{array}{l}\text { Select the most appropriate methodology and design } \\
\text { considering the research questions or hypotheses } \\
\text { as well as realities of time, resources, and probable } \\
\text { sample size. }\end{array}$ & $\begin{array}{l}\text { Will the selected design enable the collection } \\
\text { of the data to answer the research questions } \\
\text { or hypotheses as well as address the problem } \\
\text { statement? } \\
\text { - Will the sample size be appropriate for the design? }\end{array}$ \\
\hline 8. Develop data collection plan & $\begin{array}{l}\text { Identify the data to answer the research questions } \\
\text { or hypotheses and how to collect the data (e.g., } \\
\text { interviews, focus groups, observations, tested and } \\
\text { validated instruments or surveys, databases, public } \\
\text { media, and so forth). }\end{array}$ & $\begin{array}{l}\text { Is the data collection approach appropriate for } \\
\text { the design? } \\
\text { - Will the data collection approach collect the data } \\
\text { to answer all of the research questions? }\end{array}$ \\
\hline 9. Identify data analysis strategy & $\begin{array}{l}\text { Identify the appropriate data analysis, based on the } \\
\text { design, to answer the research questions. }\end{array}$ & $\begin{array}{l}\text { - Will the data analysis approach answer the } \\
\text { research questions? } \\
\text { - Is it appropriate for the design? } \\
\text { - Is it appropriate for the type of data collected? }\end{array}$ \\
\hline $\begin{array}{l}\text { 10. Synthesize to create research } \\
\text { purpose statement }\end{array}$ & $\begin{array}{l}\text { Develop a purpose statement that includes and } \\
\text { synthesizes the methodology, design, problem } \\
\text { statement, sample, and location. }\end{array}$ & $\begin{array}{l}\text { Does the problem statement clearly reflect the } \\
\text { methodology, design, problem statement, sample, } \\
\text { and location? }\end{array}$ \\
\hline
\end{tabular}




\section{METHOD}

The purpose of this study was to determine student perceptions of the learning they gained from the use of a 10-point strategic research framework within the context of a weeklong residency program. Doctoral students participated in this residency session with highly trained residency faculty who are also experienced dissertation chairs. The residency faculty delivered research intensive training on conceptualizing, developing, and writing the required elements of the 10-point strategic framework. All classroom sessions were standardized to the extent that daily content delivery and classroom activities were similarly structured. The faculty offered individualized coaching and feedback to students during daily sessions, and students were expected to continuously self-evaluate and improve upon the quality of their work.

Design

A pre-experimental one group, pre-posttest design was used for this investigation. Doctoral students completed a draft the 10 strategic points as an assignment prior to attending their residency session. On the first day of class all students completed a self-evaluation regarding their understanding of each element of this draft copy of the 10 strategic points. During the subsequent four days of intensive research training, which included faculty led conceptual, visual, and experiential activities related to developing each element of the 10-points strategic points, students revised their 10 strategic points document. On the final day of residency, students presented the culmination of their work as an oral presentation and completed the post evaluation assessing their knowledge level regarding each of the 10 strategic points. The selfassessment questionnaire was designed as a way for doctoral students to reflect on their progress during the week and to develop a plan for the next steps in developing the framework for their respective research study.

\section{Procedures}

Doctoral students were instructed to use a selfreflection questionnaire to assess their level of preand post-knowledge of the 10 strategic points. The Likert scale questionnaire used a data range from 1=strongly disagree, $2=$ disagree, $3=$ neither agree nor disagree, 4=agree, and 5=strongly agree.
The following questions were posed:

1. I have an understanding of the 10 strategic points.

2. I have an understanding of how to use the literature review to identify a gap and define the problem statement for research.

3. I have an understanding of how to use the literature review to identify a model or theory to use for my theoretical foundations.

4. I have an understanding of how synthesize the literature to help develop my 10 strategic points.

5. I have an understanding of how to develop a problem statement.

6. I have an understanding of how to develop research questions.

7. I have an understanding of how to develop a sample.

8. I have an understanding of how to describe phenomena (qualitative).

9. I have an understanding of how to describe variables (quantitative).

10. I have an understanding of how to develop hypotheses (quantitative).

11. I have an understanding of how to select a methodology (quantitative or qualitative).

12. I have an understanding of how to select a design.

13. I have an understanding of how to develop a purpose statement.

14. I have an understanding of how to select data collection approaches.

15. I have an understanding of the differences between data analysis for quantitative versus qualitative methodologies.

\section{Participants}

The 10 strategic point self-assessment questionnaires were analyzed from 135 doctoral students enrolledinanonlineEd.D. doctoral program at a university located within the southwestern United States. Doctoral students participate in face-to-face research residency training during the first and second years of the Ed.D. program. The focus of the first residency training is development of the 10 strategic points as a framework for the dissertation. As part of the residency experience, 
the doctoral students complete a pre- and postassessment of their overall learning experience and understanding of the 10 strategic points. The self-assessment data were extracted from course files from five instructors who taught the firstyear residency courses during summer 2014. The questionnaires were coded, and all identifiers were removed. Of the 147 questionnaires originally extracted, 135 questionnaires were complete and included in the final analysis. Gender and age data were not collected in this sample. The participants, all adult learners, were all at a similar level of coursework in their doctoral program and had met the prerequisites for attending the first-year residency course.

\section{Data Analysis}

Data analyses were performed treating the data as nonparametric, based on the self-assessment questionnaire values rated at the ordinal level Table 2: Descriptive statistics and frequencies $(n=135)$ and the dependent nature of the pretest, posttest scores. A Wilcoxon Signed Rank Test for pairwise comparisons was used to test for significant differences on self-assessment scores for the 15 questions. A one-tailed test was chosen because all hypotheses were directional, predicting higher rankings for the variables entered into the analysis. The Wilcoxon Signed Rank Test does not assume normal distribution for the variables of interest; however, the paired differences are assumed to be symmetrically distributed. All statistical tests were performed at alpha value (significance) of .05. In effort to reduce the chance of a Type I error, a Bonferroni correction (Armstrong, 2014) was made to adjust for multiple comparisons and account for the familywise error rate $(.05 / 15=.003)$. The adjusted alpha rate to test for significance for each individual hypothesis was set at $p<.003$. Analyses were carried out using IBM SPSS Statistics 21.

\begin{tabular}{|c|c|c|c|c|c|c|c|}
\hline & MEAN & MEDIAN & $\begin{array}{c}\% \\
\text { STRONGLY } \\
\text { AGREE }\end{array}$ & $\begin{array}{c}\% \\
\text { DISAGREE }\end{array}$ & $\begin{array}{l}\% \text { NEITHER } \\
\text { DISAGREE } \\
\text { OR AGREE }\end{array}$ & $\begin{array}{c}\% \\
\text { AGREE }\end{array}$ & $\begin{array}{c}\% \\
\text { STRONGLY } \\
\text { AGREE }\end{array}$ \\
\hline \multicolumn{8}{|c|}{ Q1Understands 10 strategic points } \\
\hline Pretest & 3.3 & 4.0 & 2.2 & 17.8 & 25.2 & 51.1 & 3.7 \\
\hline Posttest & 4.5 & 5.0 & 1.5 & 0.0 & 0.0 & 43.7 & 54.1 \\
\hline \multicolumn{8}{|c|}{$\begin{array}{l}\text { Q2 Understands role of literature review in } \\
\text { identification of gap and problem }\end{array}$} \\
\hline Pretest & 3.4 & 4.0 & 5.2 & 13.3 & 25.9 & 48.9 & 6.7 \\
\hline Posttest & 4.4 & 5.0 & 1.5 & 0.0 & 3.7 & 50.4 & 44.4 \\
\hline \multicolumn{8}{|c|}{$\begin{array}{l}\text { Q3 Understands role of literature review in } \\
\text { identification of model or theory }\end{array}$} \\
\hline Pretest & 3.0 & 3.0 & 5.2 & 23.0 & 35.6 & 34.8 & 1.5 \\
\hline Posttest & 4.2 & 4.0 & 1.6 & 0.0 & 8.1 & 53.3 & 37.0 \\
\hline \multicolumn{8}{|c|}{$\begin{array}{l}\text { Q4 Understands role of synthesis of literature } \\
\text { in the } 10 \text { strategic points }\end{array}$} \\
\hline Pretest & 2.9 & 3.0 & 7.4 & 22.2 & 38.5 & 30.4 & 1.5 \\
\hline Posttest & 4.1 & 4.0 & 1.5 & 2.2 & 8.9 & 58.5 & 29.8 \\
\hline \multicolumn{8}{|c|}{$\begin{array}{c}\text { Q5 Understands development of problem } \\
\text { statement }\end{array}$} \\
\hline Pretest & 3.2 & 3.0 & 3.0 & 22.2 & 28.1 & 43.7 & 3.0 \\
\hline Posttest & 4.5 & 5.0 & 1.5 & 0.0 & 1.5 & 41.5 & 55.6 \\
\hline \multicolumn{8}{|c|}{$\begin{array}{l}\text { Q6 Understands development of research } \\
\text { questions }\end{array}$} \\
\hline Pretest & 3.1 & 3.0 & 5.2 & 17.0 & 42.2 & 31.9 & 3.7 \\
\hline Posttest & 4.4 & 4.0 & 1.5 & 1.5 & 2.2 & 46.7 & 48.1 \\
\hline
\end{tabular}


Table 2: Descriptive statistics and frequencies $(n=135)$ Continued

\begin{tabular}{|c|c|c|c|c|c|c|c|}
\hline & MEAN & MEDIAN & $\begin{array}{c}\% \\
\text { STRONGLY } \\
\text { AGREE }\end{array}$ & $\begin{array}{c}\% \\
\text { DISAGREE }\end{array}$ & $\begin{array}{l}\% \text { NEITHER } \\
\text { DISAGREE } \\
\text { OR AGREE }\end{array}$ & $\begin{array}{c}\% \\
\text { AGREE }\end{array}$ & $\begin{array}{c}\% \\
\text { STRONGLY } \\
\text { AGREE }\end{array}$ \\
\hline \multicolumn{8}{|c|}{ Q7Understands development of study sample } \\
\hline Pretest & 3.0 & 3.0 & 5.2 & 25.2 & 37.0 & 31.1 & 1.5 \\
\hline Posttest & 4.3 & 4.0 & 1.5 & 2.2 & 3.7 & 51.9 & 40.7 \\
\hline \multicolumn{8}{|c|}{ Q8 Understands identification of phenomenon } \\
\hline Pretest & 2.6 & 3.0 & 11.9 & 36.3 & 29.6 & 22.2 & 0.0 \\
\hline Posttest & 4.2 & 4.0 & 1.5 & 1.5 & 14.1 & 48.9 & 34.0 \\
\hline \multicolumn{8}{|c|}{ Q9 Understands description of variables } \\
\hline Pretest & 2.6 & 3.0 & 9.6 & 37.0 & 32.6 & 20.7 & 0.0 \\
\hline Posttest & 3.9 & 4.0 & 2.2 & 3.7 & 17.8 & 56.3 & 20.0 \\
\hline \multicolumn{8}{|c|}{ Q10 Understands development of hypotheses } \\
\hline Pretest & 2.9 & 3.0 & 8.9 & 23.0 & 42.2 & 25.94 & 0.0 \\
\hline Posttest & 4.0 & 4.0 & 2.2 & 2.2 & 20.0 & 8.9 & 26.7 \\
\hline \multicolumn{8}{|c|}{ Q11 Understands selection of methodology } \\
\hline Pretest & 3.1 & 3.0 & 3.7 & 25.2 & 28.9 & 37.0 & 5.2 \\
\hline Posttest & 4.3 & 4.0 & 1.5 & 0.7 & 5.2 & 52.6 & 40.0 \\
\hline \multicolumn{8}{|c|}{ Q12 Understands selection of design } \\
\hline Pretest & 2.6 & 3.0 & 8.1 & 38.5 & 39.3 & 13.3 & .7 \\
\hline Posttest & 4.0 & 4.0 & 1.5 & 3.0 & 10.4 & 63.0 & 22.2 \\
\hline \multicolumn{8}{|c|}{$\begin{array}{l}\text { Q13 Understands development of } \\
\text { purpose statement }\end{array}$} \\
\hline Pretest & 3.2 & 3.0 & 5.2 & 16.3 & 34.1 & 41.5 & 3.0 \\
\hline Posttest & 4.4 & 4.0 & 1.5 & 0.0 & 2.2 & 50.4 & 45.9 \\
\hline \multicolumn{8}{|c|}{ Q14 Understands data collection approaches } \\
\hline Pretest & 2.6 & 2.0 & 12.6 & 37.8 & 29.6 & 20.0 & 0.0 \\
\hline Posttest & 3.9 & 4.0 & 2.2 & 3.7 & 10.4 & 60.0 & 23.7 \\
\hline \multicolumn{8}{|c|}{$\begin{array}{l}\text { Q15 Differentiates between qualitative and } \\
\text { quantitative methods }\end{array}$} \\
\hline Pretest & 2.9 & 3.0 & 9.6 & 29.6 & 25.2 & 29.6 & 6.0 \\
\hline Posttest & 4.1 & 4.0 & 1.5 & 1.5 & 12.6 & 55.6 & 28.9 \\
\hline
\end{tabular}

\section{RESULTS}

Descriptive statistics for the individual questions were analyzed non-parametrically. Median data and frequencies were reported for pretest and posttest scores. Due to the relatively large sample size, the Likert scale responses could approximate scale level data, where mean values can be reported for descriptive purposes. Table 2 provides a summary of the descriptive statistics for each question including mean, median, and frequency of responses for each question represented as a percentage.

The results of the descriptive statistics indicate that the mean and median values for each question increased by at least one point. In addition, the frequency data illustrate a significant positive shift in ratings from the pretest to posttest for all questions. For example, for the first question ranking the overall understanding of the 10 strategic points model, students indicated 54.8\% 
agreement (agree+strongly agree) at the pretest and $97.8 \%$ at the posttest. This trend continues with the remainder of the questions. For the pretest, the percentage agreement (agree+strongly agree) ranged from $20.0 \%$ to $55.5 \%$. At the posttest, the percentage agreement ranged from $75.6 \%$ to $97.8 \%$. These data suggest the students perceived their overall understanding of the 10 strategic points and the various elements of the model to be much higher following the residency experience. These data are supported by the analysis of the rankings using the Wilcoxon Signed Ranked test.

Table 3 indicates the number of doctoral students who gave lower ratings (Negative Ranks) from pretest to posttest on their understanding of the 10 strategic points, the number of students who gave higher ratings (Positive Ranks), and the number who gave equal ratings (Ties). A one-tailed Wilcoxon Signed Rank Test indicated that for all questions, significantly more students perceived higher overall understanding of the 10 strategic points compared to students who perceived their understanding to have decreased or stayed the same.

\section{DISCUSSION}

\section{Implications}

There are a number of factors requiring universities to continue to identify approaches that will improve the quality, efficiency, and effectiveness of their doctoral programs. Attrition rates from these programs are high (Ivankova \& Stick, 2007; Nettles \& Millet, 2006). Often, the time to complete these programs is lengthy, in part, due to the lack of preparedness on the part of the doctoral students (Anderson et al., 2013). The increased accountability and focus on the effectiveness of doctoral programs (Anderson et al., 2013) require continued improvement in the programs not only from an academic perspective, but also from the student perspective. Part of improving university programs involves providing appropriate learner-centered pedagogy to develop needed research and writing skills (Wagner et al., 2011). The results of this study suggested that doctoral students perceived their understanding of the foundational elements of a dissertation to have increased as a result of the conceptual, visual,

Table 3: Student rankings for elements of 10 strategic points

\begin{tabular}{|c|c|c|c|c|c|}
\hline & $\begin{array}{l}\text { NEGATIVE } \\
\text { RANKS }^{\mathrm{a}}\end{array}$ & $\begin{array}{l}\text { POSITIVE } \\
\text { RANKS }^{b}\end{array}$ & Ties $^{c}$ & $Z^{\mathrm{d}}$ & $p$ \\
\hline Q1 Understands 10 strategic points changes from pre to posttest & 2 & 107 & 26 & -8.820 & $.000^{*}$ \\
\hline $\begin{array}{l}\text { Q2 Understands role of literature review in identification of gap and problem changes from } \\
\text { pre to posttest }\end{array}$ & 4 & 92 & 39 & -7.959 & $.000^{*}$ \\
\hline $\begin{array}{l}\text { Q3 Understands role of literature review in identification of model or theory changes from } \\
\text { pre to posttest }\end{array}$ & 3 & 107 & 25 & -8.692 & $.000^{*}$ \\
\hline $\begin{array}{l}\text { Q4 Understands role of synthesis of literature in the } 10 \text { strategic points changes from } \\
\text { pre to posttest }\end{array}$ & 3 & 96 & 36 & -8.264 & $.000^{*}$ \\
\hline Q5 Understands development of problem statement changes from pre to posttest & 2 & 10 & 23 & -8.902 & $.000^{*}$ \\
\hline Q6 Understands development of research questions changes from pre to posttest & 1 & 112 & 22 & -9.264 & $.000^{*}$ \\
\hline Q7 Understands development of study sample changes from pre to posttest & 3 & 110 & 22 & -8.812 & $.000^{*}$ \\
\hline Q8 Understands identification of phenomenon changes from pre to posttest & 3 & 115 & 17 & -9.036 & $.000^{*}$ \\
\hline Q9 Understands description of variables changes from pre to posttest & 5 & 98 & 32 & -8.489 & $.000^{*}$ \\
\hline Q10 Understands development of hypotheses changes from pre to posttest & 5 & 97 & 33 & -8.302 & $.000^{*}$ \\
\hline Q11 Understands selection of methodology changes from pre to posttest & 2 & 99 & 34 & -8.609 & $.000^{*}$ \\
\hline Q12 Understands selection of design changes from pre to posttest & 7 & 114 & 14 & -9.068 & $.000^{*}$ \\
\hline Q13 Understands development of purpose statement changes from pre to posttest & 3 & 102 & 30 & -8.377 & $.000^{*}$ \\
\hline Q14 Understands data collection approaches changes from pre to posttest & 3 & 110 & 22 & -9.031 & $.000^{*}$ \\
\hline Q15 Differentiates between qualitative and quantitative methods changes from pre to posttest & 4 & 98 & 33 & -8.229 & $.000^{*}$ \\
\hline
\end{tabular}

a Posttest score less than pretest score |b Posttest score greater than pretest score $\mid c$ Posttest score equals pretest score $\mid d$ Posttest score equals pretest score

* Significant at $p<.003$ 
and experiential activities related to developing each element of the 10 strategic points during the residency experience. Therefore, this type of instruction offered in the context of a doctoral residency program may be one strategy that can improve the effectiveness and efficiency of both student learning and doctoral programs

There are many different factors to consider when designing doctoral programs (Jones, 2013). One approach is to ensure the programs are systematically developed, as structured and systematic instruction offers students a clear path to both course and degree completion (Anderson et al., 2013). In light of the structure of the residency program presented in this study, student learning may increase when the curriculum is well thought out, and provides both experiential and social learning opportunities, as well as time for selfassessment. Providing a clear set of objectives as well as mental models used throughout the program can contribute to this systematic approach. The 10 -point strategic framework provides a mental model or strategic framework for doctoral students to use when developing the approach to their dissertation research.

Another area to consider in doctoral programs is to ensure that socialization, including adapting the values, knowledge, and capabilities of doing academic research, occurs. Enabling the students to address various innate psychological needs, such as autonomy and a sense of relatedness, may provide the motivation needed for student success (Mason, 2012). Additionally, self-reflection allows doctoral students the opportunity to assess the effectiveness of their learning, which was offered during this weeklong course. At the same time, there is still an opportunity to identify additional approaches to further increase student understanding of the dissertation and research process.

The residency classroom environment allowed the students to work autonomously on their own dissertations and at the same time receive coaching from highly experienced and successful chairs may have contributed to this socialization. Universities are providing additional focus on developing the research skills and the pedagogy to address this need (Wagner et al., 2011).

The dissertation phase of the doctoral program can be very challenging to students due to its unique nature. Students need to put in an extraordinary amount of effort if they are to persist and graduate (Lindsay, 2015). The residency program design included the 10-point strategic framework as a mental model and a tool to enable them to successfully develop and align the 10 strategic points that would provide a plan, and a vision, for their dissertation research. The integration of the 10-point strategic framework, coaching by experienced, successful chairs, and the autonomy within the class to work on their own dissertations was structured to enable the cognitive and social development for successful completion of their dissertation.

\section{Limitations}

There were a number of limitations to this research. The research was limited to obtaining the students' perceptions of their learning. The research did not include the actual assessment of student capability to produce the 10 strategic points for their dissertation prior to and after the program. This study involved the use of assessment data from only five classes. All of the classes used in this study were located in one city. Conducting the assessment in other cities with a more diverse population will help to extend the generalizability of the findings. The actual assessment of social reasoning as well as the realization of socialization to the culture of research was not a part of the formal assessment.

\section{Recommendations}

The research conducted on this residency program was only a beginning step in the process of designing and assessing this program. This type of research, where students assess their own level of learning and development, can directly contribute not only to making the program more effective and efficient. This research can also help identify ways to realize continued improvement in the satisfaction of these students in terms of their learning, which should lead to increased persistence as more students have the capability to complete their dissertation. This research should continue with the intent to continue to improve this program.

This research identified the positive students' perceptions of their learning as a result of the program. However, it did not identify if that resulted in a significant improvement in the actual development of the 10 strategic points plan for their 
research. Conduct additional research to assess the students' ability to create the 10 strategic points plan for their dissertation before and after the program. This additional research would assess the plan students create in a pre-course assignment and the plan they create during this residency program.

The program design had the intention of enabling the socialization of the students to the culture of academic and profession research. However, this research did not directly the attainment of these goals. Adding questions to assess the attainment of their design goals would expand this research and address additional needs identified by other researchers in areas such as socialization.

Other universities who have developed conceptual frameworks or mental models could do similar research. These universities could not only share these models but also research their effectiveness at various levels. Conduct this assessment at the knowledge, skill, and application levels. Moreover, students can be engaged in this process to ensure their opinions are included to enable increased student satisfaction and persistence.

\section{CONCLUSION}

Universities are identifying different approaches to improving the effectiveness and efficiency of their doctoral programs. These changes are important in increasing the graduation rates and reducing the time it takes a student to complete a doctorate. Changes are being made to the doctoral curriculum that focuses on more than just knowledge acquisition. Challenges include improving student research skills as well as socialization to the culture of research within their field. Students play an important part in helping to address these challenges. This study reports both the approach used in a doctoral residency program as well as the doctoral student perceptions regarding learning acquired during this weeklong residency program. They were exposed to a learning environment that included (1) a strategic framework designed to conceptualize the design for their dissertation study, and (2) experienced chairs providing coaching and helped socialize them to the academic research approach and culture.

During the residency, students use a strategic 10 -point process, founded on theories and models from the fields of education and psychology, to develop a conceptual understanding and blueprint for their research. The 10-point model provides a multi-faceted approach to enabling doctoral students to conceptualize the design for their own doctoral dissertation working with an environment that supports cognitive and social development. The intent of this approach to learning is to provide students with a model and faculty feedback to create an aligned research study, thus, enabling students to design and conduct research and complete both their dissertations and the online doctoral program in a timely fashion.

Using a simple quantitative, pre-experimental, one group pre-posttest, design, students responded to a questionnaire regarding their understanding of the 10 required components of the study on the first and last day of the residency program. Data were analyzed using Wilcoxen Signed Rank Test. The results indicated there was a significant improvement in student self-reported learning and understanding of the 10-point strategic framework model between the pre-post test results.

Opportunities remain to assess the effectiveness of this approach in terms of the actual improvement in the student's ability to apply this model to define their dissertation research. A qualitative study to understand, from the student and faculty perspective, the factors that contribute to the success of this program as well needed improvements can define the design approaches to creating residency programs in doctoral programs. At the same time having various universities identify and assess specific mental models and program designs that they find effective in advancing the students ability to develop and execute a plan for their dissertation research will help to address the challenges faced by doctoral programs and improve their effectiveness and efficiency. 


\section{References}

Alfieri, L., Brooks, P. J., Aldrick, N. J., \& Tenenbaum, H. R. (2010). Does discovery-based instruction enhance learning? Journal of Educational Psychology, 103(1), 1-18.

Anderson, B., Cutright, M., \& Anderson, S. (2013). Academic involvement in doctoral education: Predictive value of faculty mentorship and intellectual community on doctoral education outcomes. International Journal of Doctoral Studies, 8, 195-201.

Armstrong, R. A. (2014). When to use the Bonferroni Correction. Opthalmic Physiological Optics, 34, 502-508.

Brew, A. (2003), Teaching and research: New relationships and their implications for inquiry-based teaching and learning in higher education. Higher Education Research and Development, 22(1), 3-18.

de Valero, F. Y. (2001). Departmental factors affecting time-todegree and completion rates of doctoral students at one landgrant research institution. The Journal of Higher Education, 72(3), 341-367.

Glenberg, A. M., \& Langston, W. E. (1992). Comprehension of illustrated text: Pictures help to build mental models. Journal of memory and Language, 31(2), 129-151.

Ivankova, N. V., \& Stick, S. L. (2007). Students' persistence in a distributed doctoral program in educa-tional leadership in higher education: A mixed methods study. Research in Higher Education, 48(1), 93-135. doi:10.1007/s11162-006-9025-4

Jimenez, C. (2011). Predictors of well-being and depression among Latino college students. Ph.D. dissertation, University of Houston, United States-Texas. Retrieved from Dissertations \& Theses: Full Text (Publication No. AAT 3485056).

Jones, M. (2013). Issues in doctoral studies-forty years of journal discussion: Where have we been and where are we going? International Journal of Doctoral Studies, 8, 83-104.

Lindsay, S., (2015). What works for doctoral students in completing their theses? Teaching in Higher Education, 20(2), 183-196.

Mason, M. M. (2012). Motivation, satisfaction, and innate psychological needs. International Journal of Doctoral Studies, 7, 259-277.

Nettles, M. T., \& Millett, C. M. (2006). Three magic letters: Getting to Ph.D. Baltimore: John Hopkins University Press.

Piaget, J. (1980). The psychogenesis of knowledge and its epistemological significance. In M. Piattelli-Palmarini (Ed.). Language and learning (pp. 23-54). Cambridge, MA: Harvard University Press.
Raskin, J. D. (2002). Constructivism in psychology: Personal construct psychology, radical constructivism, and social constructivism. American Communication Journal, 5(3), 1-26.

Wagner, C., Garner, M., \& Kawulich, B. (2011), The state of the art of teaching research methods in the social sciences: towards a pedagogical culture. Studies in Higher Education, 36(1), 75-88.

Walker, G. E., Golde, C. M., Jones, L., Bueschel, A. C. \& Hutchins, P. (2008). The formation of scholars: Rethinking doctoral education for the twenty-first century. San Francisco, CA: Jossey-Bass.

Wao, H. O., \& Onwuegbuzie, A. J. (2011). A mixed research investigation of factors related to time to the doctorate in education. International Journal of Doctoral Studies, 6 , $115-134$. 